\title{
THE RELATION BETWEEN PROBLEM AREAS AND STAGES OF COMPUTER IMPLEMENTATION
}

\author{
Alfons ten Brummelhuis and Tjeerd Plomp \\ Department of Education, University of Twente, The Netherlands
}

Introduction and Research Questions

The introduction of computers in education is a complex innovation in which many obstacles need to be overcome before it is possible to speak of a successful implementation. When the Comped study was designed during 1985-1987, it was known that in many countries the number of computers in schools had increased considerably over the years. Yet it was reported that little progress had been made in integrating computers in existing lesson practices: few teachers were actual users, software use was often restricted to drill and practice activities, and the integration of computers in the curriculum was poor (Pelgrum \& Plomp, 1991; p.4).

From the literature on the implementation of innovations, we know that there are four categories of important factors for a successful integration of computers in education: national context, school organization, external support, and innovation characteristics (Fullan, Miles \& Anderson, 1988; Van den Akker, Keursten \& Plomp; 1992). Restricting ourselves to only the two categories which refer most to school problems, typical problems which may hamper the introduction of computers on school level are:

with respect to school organization:

- lack of encouragement and support from school administrators and principals, especially in the provision of facilities for training, acquisition of hardware and software, rearrangements of time tables, and other organizational measures;

- the school climate is negative and teachers are not mutually supportive;

- there is no long term security of supply and maintenance of hardware and software; with respect to innovation characteristics:

- need and relevance: is there a need for using computers, and what is the priority of computer usage in comparison with other concerns?

clarity: how clear are the goals, the essential features, and the practical implications of computer use to those who are supposed to work with computers in the schools? complexity: how difficult is it to introduce computers in the curriculum and the instructional practice, and how drastic are deviations from existing practices and beliefs? 
- availability: do schools have enough computers and software for instructional use?

- quality and practicality: how well developed and tested are the educational software products, and to what extent is the expected impact empirically proven?

This kind of questions are often asked by teachers and other practitioners, who ultimately are the central actors in the implemention of computers in educational practice. Weaknesses in one or more of the categories mentioned above may cause major obstructions in the implementation of computers on school and classroom level. Pelgrum and Plomp (1991) report that integration of computers in the practices of the schools is developing very gradually: many schools use computers for instructional activities, schools do have a fair amount of educational software, and the number of teachers involved in using computers is yearly increasing in all participating countries. However, they also conclude that in many countries only a small percentage of teachers in secondary schools use computers in their lessons. The kind of use is rather traditional because drill and practice is most frequently mentioned as a didactical approach for computer use. From an implementation perspective in many countries the introduction of computers is in an early stage. On the other hand, it is promising that in the USA in four years time about twice as many teachers of mathematics, science and mother tongue were going to use computers in their lessons.

In order to explore in what areas policy makers, support institutions and school administrators might take measures for improving the process of implementing computers in educational practice, one might look at the problems users of computers are experiencing, and at the reasons why non-users say they are still non-users. In the Comped study principals, computer coordinators and teachers in computer using schools were asked to indicate on a list of 28 potential obstacles what they in their situation, and from their perspective see as problems which are hampering the introduction of computers in their school and classroom practice, while principals from non-using schools and nonusing teachers were asked to indicate on the same list their reasons for not being involved with computers for instructional purposes.

The number and kind of problems during the stages of adoption and implementation of computer use at schools is the central topic in this article. The research questions addressed in this article are:

which problems do computer users experience at school and classroom level in using computers, and what are the reasons for non-users' lack of use of computers for instructional purpose?

- $\quad$ are there any relations between the degree of implementation of computer use at school level and the type of problems that are expenenced?

In this paper we will analyze the data for lower secondary education from four countries: France, Japan, the Netherlands, and the USA. These countries are selected for this analysis for, amongst others, the following reasons:

France has a centralized educational system; already in the late 1970 s the French government took the initiative for a national policy for introducing computers in secondary schools; France also stimulated courseware development on a national level, and schools received vouchers to buy 'nationally approved' courseware; 
- Japan, which in many respects sets an example for other industrialized countries, started only recently (1985) with an active stimulation policy in this area; Japan has a centralized educational system;

- the Netherlands in principle has a decentralized educational system, but the national government developed from the early 1980 s a very active stimulation policy with respect to the introduction of computers in education; between 1985 and 1989 all junior secondary schools were equipped with 11 MS-DOS computers (partly in a network) and received programs such as a word processor, database, spreadsheet, while also a national teacher inservice training program was also implemented, and a national courseware development project was established;

the USA, having a decentralized educational system (education is a responsibility of the states and the counties) is known as the fore-runner in this area. Pelgrum and Plomp (1991) show that roughly spoken the developments with regard to the introduction of computers in education in many industrialized countries in 1989 were at the same level as in the USA in 1985-1986.

In the next section we first will present some context data about the instruments used and the respondents. Then an exploratory analysis of the problems of users and the reasons of the non-users will be given, followed by an analysis in which intensive using schools are being contrasted with 'light' using schools. In the last section some conclusions and recommendations for policy makers at school level and beyond will be proposed.

\section{Some Context Data}

In France, Japan, the Netherlands and the USA, data were collected in computer using schools from principals, computer coordinators, teachers of computer education (often called computer literacy, informatics, etc), and from computer using as well as nonusing teachers of mathematics, science or mother tongue (called teachers of existing subjects). It appeared that in 1989 at lower secondary school level an introductory course in computer education was being taught in $24 \%$ of the lower secondary level schools in Japan, in $92 \%$ of these schools in the Netherlands and in $53 \%$ in the USA. However, in France 'teaching about computers' is a separate course only in a small percentage of lower secondary schools $(10 \%)$; in the other schools this is part of other courses, for example general technology $(54 \%)$, or mathematics $(13 \%)$. Therefore for France only data from teachers of existing subjects were included. In the non-using schools data were collected from principals.

Excluded from our analysis are those respondent categories from which data of less than 50 respondents were available which appear to be the principals of non-using schools in France and the Netherlands. The same respondent category is non-existent in the USA, as all schools in the sample are using computers.

The problems in using computers, and the reasons for non-use are divided into five categories: hardware, software, instruction, organization, and other. Table 1 contains for each problem (and reason for non-use), the percentage of respondents checking this problem/reason. 


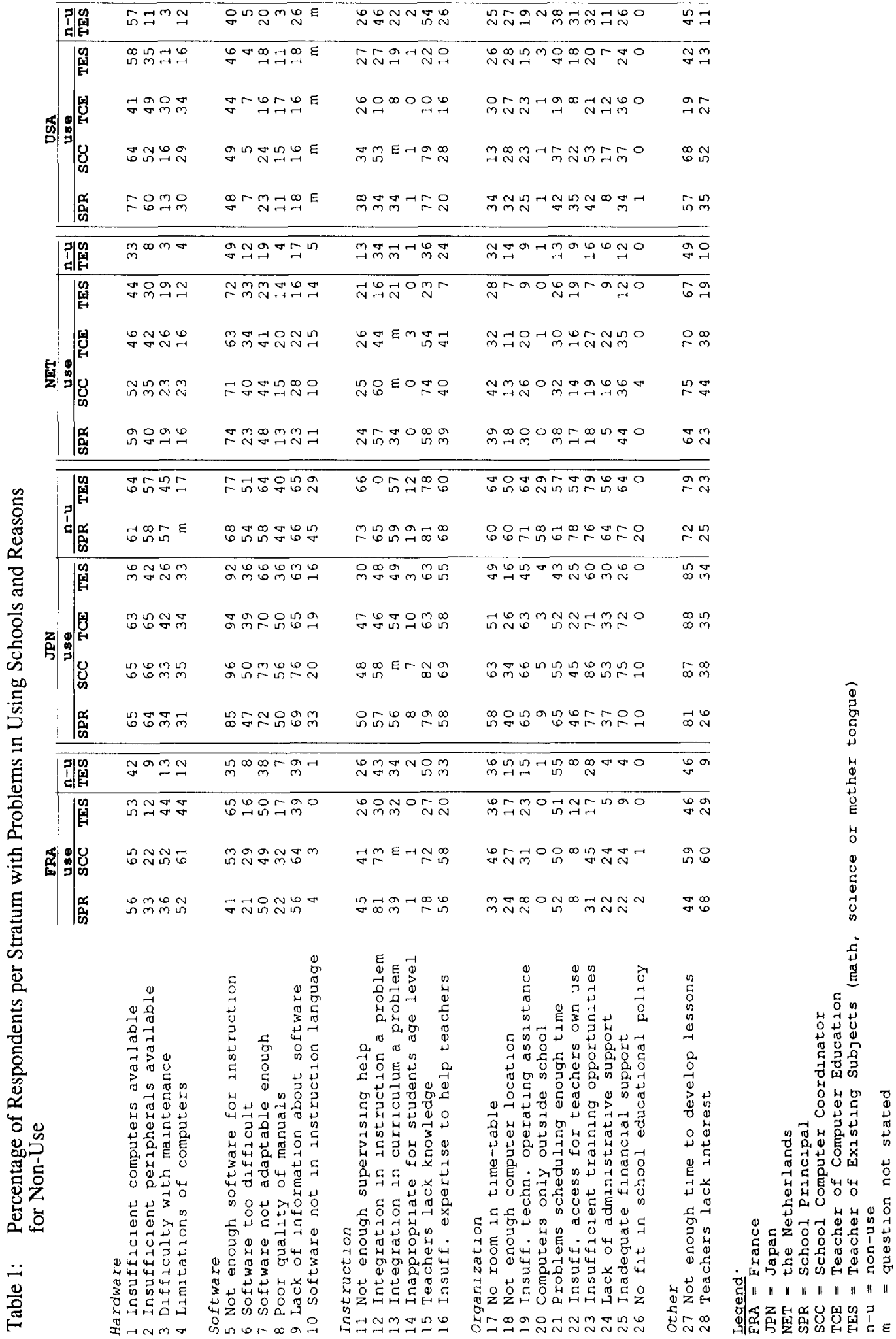




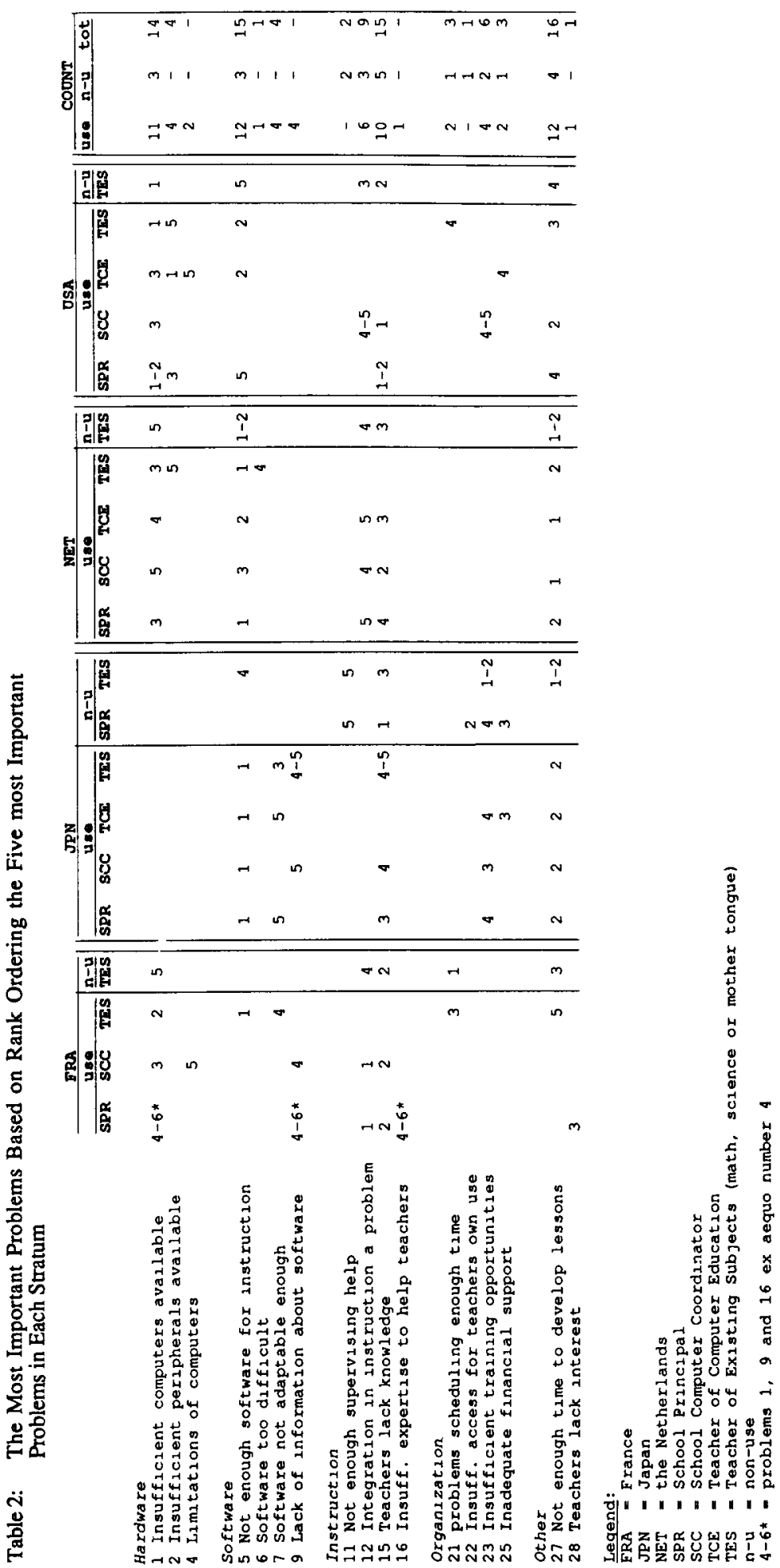




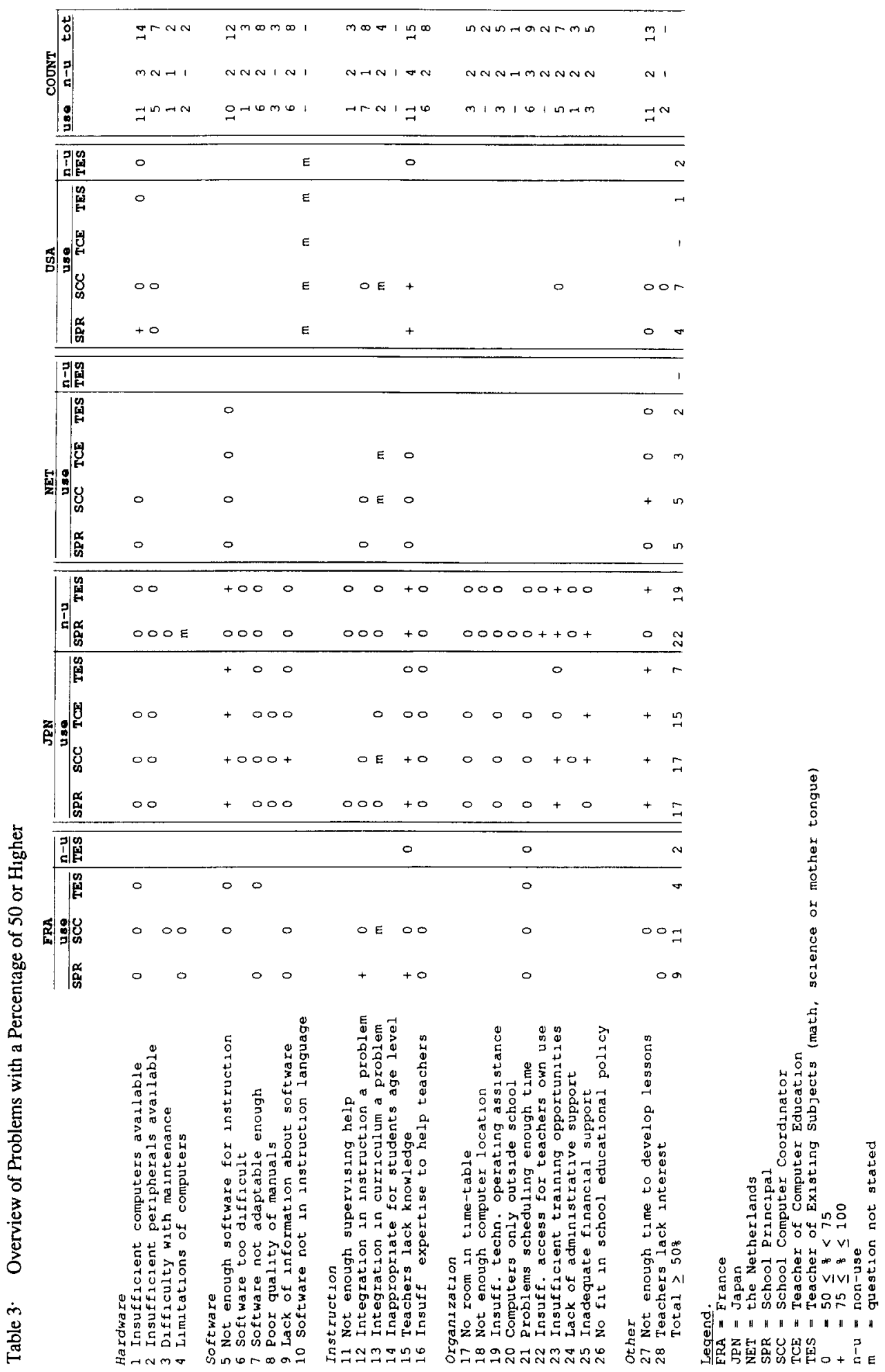


A first conclusion from the data is that there are clearly some 'non-problems':

- Item 14: hardly anybody believes that the use of computers is inappropriate for students in secondary school; a percentage $>10$ is only found for non-using principals and teachers in Japan;

- Item 20: the lack of availability of computers in school is only mentioned by a meaningful percentage of principals of non-using schools (58\%) and non-using teachers $(29 \%)$ in Japan;

- Item 26: the possibility that the use of computers would not fit in with the school's policy is neither a problem, nor an argument for not using computers; the only percentage $>10$ is found among the non-using principals in Japan.

One way of determining the most important obstacles in using computers is looking at the items which have the highest percentages. Per stratum the scores on the 28 items in Table 1 are rank-ordered, and only the five most important ones are selected.

Table 2 contains the most frequently mentioned items with their rank order per stratum:

- Item 27, not enough time to develop lessons with computers: this is an important problem across categories; all categories of using and non-using teachers of existing subjects have this time problem in the top five;

- Item 1, insufficient computers available: here Japan is clearly different from the other countries, where this item belongs to the top five in all categories of respondents, users as well as non-users;

- Item 5, not enough software for instructional purposes available: although this one is not among the top five of the using principals and computer coordinators in France, it should be notified that all categories of using teachers in all four countries have the lack of software as the number 1 or 2 problem;

- Item 15, teachers lack knowledge: all non-using categories mention this as one of the most important reasons for not using computers. It is interesting to observe that in all four countries the principals and computer coordinators mention lack of knowledge of teachers as an important problem, while in France, the Netherlands and the USA the category of using teachers of mathematics, science and mother tongue does not have this in the top five. This suggests that many using teachers, who are no specialists in the area of computers, do not see their level of knowledge as a major obstacle;

- Item 12, integration in classroom practice: given the scores, one might call this one a 'second level' problem. In Japan, other problems are apparently more dominant; but according to the computer coordinators in France, the Netherlands and the USA this is a major problem in the schools. Non-using teachers also score this item in the top five.

Looking at the top-five problems does not take into account that the percentage scores may differ enormously between countries. For example, the most important problem in the category using principals in the USA has a score of $77 \%$, which is the percentage of the number four problem in Japan; and, in the same category, the number 
five problem in the USA has a lower percentage (48\%) than the number 17 in Japan. We therefore marked all scores with a percentage of 50 or higher. The results are shown in Table 3.

First, the results of Table 3 confirm those based on Table 2: the same four items appear to be the top four obstacles. It should be noticed that they all refer to conditional problems. They involve lack of hardware, software, knowledge and time. Clearly, users as well as non-users feel that these conditional factors are primary obstacles: it seems that what users experience as major problems, constitute for non-users (who must have heard about these problems, as they are not experiencing these themselves!) reasons not to invest time and efforts in getting involved with using computers.

Secondly, a more detailed inspection of Table 3 reveals some interesting phenomena. It is obvious that the Japanese educators at all levels in junior secondary schools feel that they experience most problems. Some of the problems only in Japan score higher than $50 \%$, such as 'no room in the time table to let students learn about computers' (17), 'not enough technical assistance for operating and maintaining computers' (19), 'insufficient training opportunities for teachers' (23), 'lack of support or initiatives from administrators' (24), and 'inadequate financial support' (25). If we compare these factors with those mentioned in the literature on implementation of change as important for influencing the implementation process (e.g. Fullan, 1982; Fullan, Miles \& Anderson, 1988), then we must conclude that, in 1989, many Japanese schools still struggled with the basic and most absolutely necessary implementation conditions. Whether this special position of Japan is due to the rather late start of a national stimulation policy (1985: the national government started to subsidize half of the amount necessary for the purchase of hardware), or whether (also) other factors are playing a role needs further analysis. It might be that the repeated survey in 1992 will shed more light on this.

Another observation from Table 3 is that in all countries principals and computer coordinators experience many more problems than computer using teachers. Further, the low number of items that scored higher than $50 \%$ by non-using teachers in France, the Netherlands and the USA suggests that non-users apparently mention a variety of reasons for not being involved with computers in their instructional practice; 'teachers lack knowledge of and skills for using computers for instructional purposes' (15) is the only reason which has a score higher than $50 \%$ in two countries .

\section{Contrast Analysis}

To find out if there is any relationship between the degree of implementation of computer use and the type of problems which are experienced, a comparison was made between the intensive using schools and the relatively 'light' using schools. To distinguish these two groups for each country a measure indicating the level of computer use was calculated. This was done by counting per grade level the number of subjects in which computers were used. For example, if in a school in grade 7 computers are being used in three subjects, in grade 8 in four subjects, and in grade 9 in two subjects, then for this school this variable has the value 9 . After ranking the schools for each country on this score, the upper thirty per cent was identified as the schools with a high level of computer use and the lower thirty per cent as the schools with a low level of computer use. The intermediate forty percent of cases was left out of the contrast analysis. Because the 
information from the technical questionnaire was used for establishing the level of computer use, all schools without a completed technical questionnaire were excluded. Also categories with less than 50 cases were excluded. For this reason the using teachers in existing subjects from the Netherlands are not included in the contrast analyses.

Table 4 shows the mean and the standard deviation of the scores that underlies the level of computer use for each of the countries.

Table 4: Mean and Standard Deviation of the Score Indicating the Grades and Subjects in Which Computers Are Used

\begin{tabular}{lccrr}
\hline & \multicolumn{2}{c}{ low use } & \multicolumn{2}{c}{ high use } \\
& mean & sd & mean & sd \\
\hline France & 4.3 & 1.5 & 14.8 & 3.0 \\
Japan & 2.0 & 0.8 & 10.4 & 5.0 \\
Netherlands & 1.5 & 0.5 & 9.7 & 3.5 \\
USA & 2.8 & 1.1 & 13.2 & 3.7 \\
\hline
\end{tabular}

Looking at the mean scores it becomes clear that the level of computer use differs between countries. The reason for these differences is that the level of use score represents a relative measure which is related to the specific situation in a country. As noted before in France 'teaching about computers' is part of other courses and in the Netherlands it is a separate course at most schools. This could be the reason why for example in the low use category, the mean score in France is nearly three times as high as in the Netherlands. Table 5 presents the percentages of respondents in schools with a high (h) and schools with a low (1) level of computer use per stratum; the significant differences at $5 \%$ and $10 \%$ level are also indicated. The percentages for the categories without a significant difference are not included in this table for convenience of comparison, but can be found in Table 1.

The results from the contrast analyses illustrate that the significant differences between high and low level of computer use are mostly such that low level using schools experience more problems (downward arrow in Table 5). In a limited number of cases schools with a high level of computer use have more problems with a possible obstacle than schools with a low level of computer use (upward arrow in Table 5). In France, the Netherlands and the USA the number of significant differences between low and high level use is small. Also the mean number of problems marked by respondents in the questionnaires (see at the bottom of Table 5) between low and high level use hardly differs in these countries. This in contrast with Japan where low and high level use vary widely especially in problems related to the organizational aspect of computer use; the mean number of problems at high level use is always below the low level use. As mentioned before the most important obstacles are: lack of hardware, software, knowledge and time. The contrast analyses answer the question whether schools with a high level of use have succeeded more in overcoming these problems than schools with a low level use. 


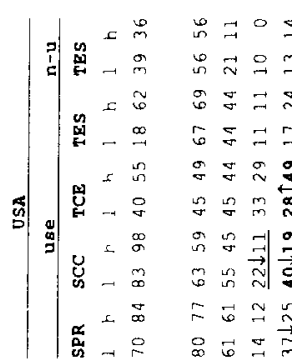

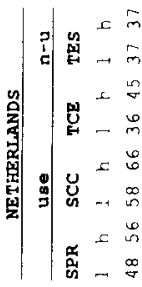

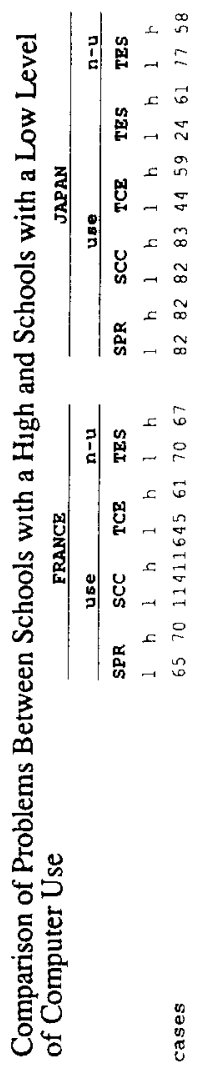

ले ज्ञे $=0$

6) î. in $\approx$

$\stackrel{m}{\vec{m}} \mid$\begin{tabular}{lll}
$\infty$ & $m$ & $m$ \\
\hdashline & $m$ & $m$
\end{tabular}

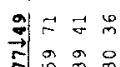

피요용

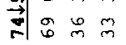

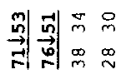

$\underset{\sim}{\infty}-\infty$

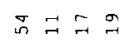

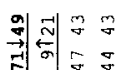

$\overline{8}$
$\sim$

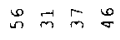

$\vec{b} \approx$ 学官

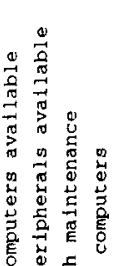

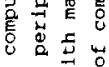

$\Rightarrow \stackrel{m}{\vec{F}}=\vec{m} m$

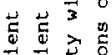

$\frac{\ddot{n}}{\ddot{0}}$ $\neq m \approx m \approx$

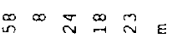

i 요 $\vec{\sim} \vec{F}$

$\infty a m \underset{\sim}{\sim}$ 인

$m \infty \stackrel{\sim}{\sim} \infty$

ज十 $\approx \cong 0$

원

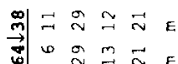

o $\begin{aligned} & 0 \\ & 2\end{aligned}$

a $=\sigma^{\infty} \approx$ 的

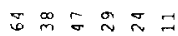

उष्व

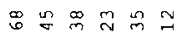

남

$\left.\therefore \stackrel{n}{m}\right|^{\infty} \vec{N}^{a}$

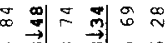

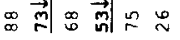

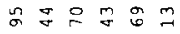

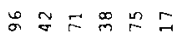

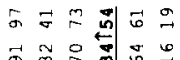

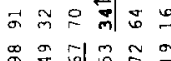

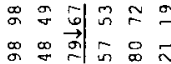

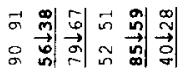

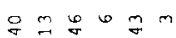

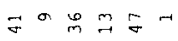

은 은

$\because 2 m_{n \rightarrow \infty}^{\infty} \propto$

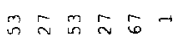

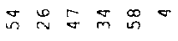

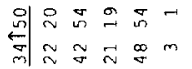

$\approx$ in $\vec{m}^{m} \mathbb{b}_{0} \sigma$

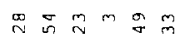

N

$\stackrel{\infty}{\sim} \approx 0=\Xi$

$\rightarrow$ in 0 o 0 개

$\stackrel{\infty}{N}$ in $m \circ \overrightarrow{\text { of }}$

的 $\mathrm{E}+\infty \mathrm{D}$

$\vec{m} \bar{n} E^{N} \approx \tilde{\sim}$

की

乔 $\vec{m} \rightarrow \underset{\infty}{m}$

$\exists \stackrel{m}{\rightarrow} \vec{\sigma}^{m}$ 少

$\underset{\sim}{\vec{n}} \underset{m}{ } \circ \underset{m}{\sim}$

舟品

党

N $\overrightarrow{0}$ E

ป

iv 哓

त $\vec{b} \mid \vec{\sigma} 0$ 品

佂

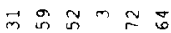
₹

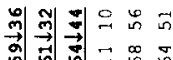

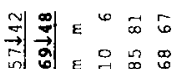

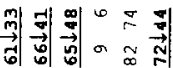

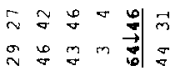

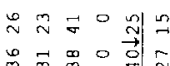

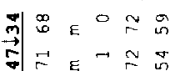

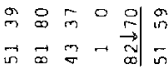

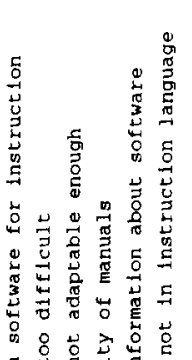

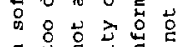

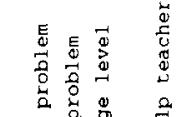

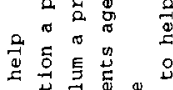

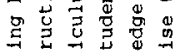

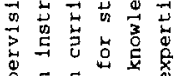

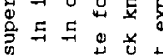

등 $\approx 0 \approx m$ in

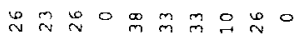

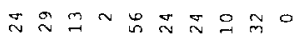

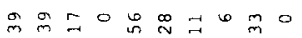

$m \mathbb{N}$ 워

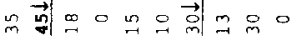

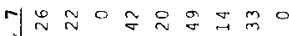

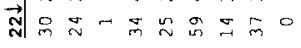

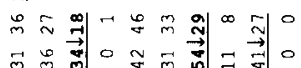

$\infty \begin{array}{lllll}1 & 0 & 0 & 0 & 0 \\ \infty & 0 & 0 & 0\end{array}$

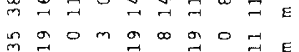

윔

$\vec{\nabla} \infty \underset{\sim}{\sim} m \vec{m}-\vec{r} \approx \stackrel{\infty}{\sim} \vec{m} E$

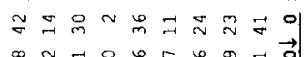

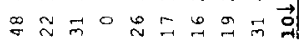

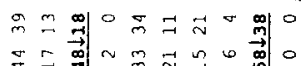

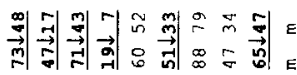

ㅁํㄱㅇ

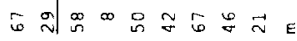

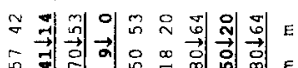

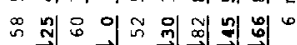

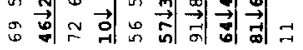

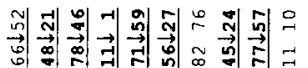

하궁요의

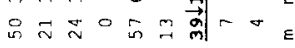

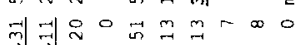

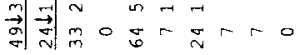

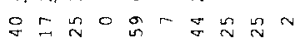

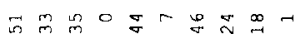

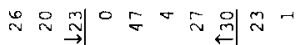

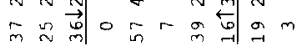

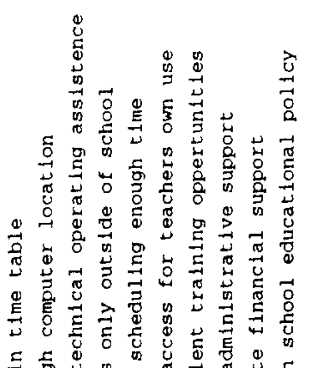

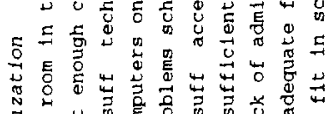

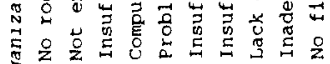

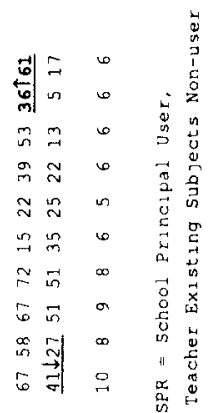

Q $\Rightarrow$ 的 $\overrightarrow{0}$ is

\& in in

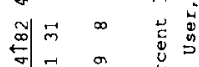

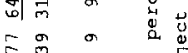

เ

ปั

요

त

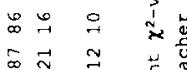

의 으

$\infty m \stackrel{m}{m} \vec{E}$

क्ष

क

a

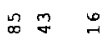

冓 은

$\stackrel{\infty}{\infty} \stackrel{\infty}{\sim}$

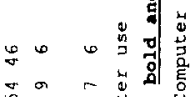

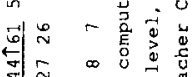

की

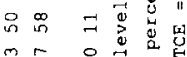

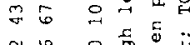

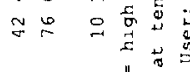

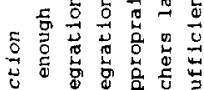


For the Netherlands and the USA the insufficient availability of computers is as big an obstacle for both levels of computer use. In France a difference appears only with the using teachers in existing subjects; the other categories of respondents feel no difference in the degree of lack of computers. In Japan all categories of respondents differ widely which indicates that availability of hardware is a cause for the difference between low and high level use.

The availability of software is a similar problem for nearly all strata at both levels of use. Only in the USA the principals of schools with a high level use experience the lack of software (significantly) less as a problem than their colleagues of schools with low level use. In France we see a reverse picture with regard to the principals. The lack of knowledge of teachers in Japan, the Netherlands and the USA is approximately equal in both levels of use. Only France has significant differences in three out of four categories of respondents which shows that the amount of knowledge teachers have in using computers differs widely between low and high level use, which might be related to the fact that most 'learning about computers' takes place via existing subjects.

In most cases the availability of time for developing lessons is a comparable problem for both levels of use. It is interesting that the three significant differences in it have to do with teacher level and show a growth of this problem when computer use at school level increases. When we look at the five most important problems (calculated as in Table 3) in each category we find that there is hardly any difference in the kind of problems between low and high level use. For both levels the four conditional factors: lack of hardware, software, knowledge and time are the most important obstacles in implementing computers. Within countries we generally find that the percentages of problems in schools with low use exceed those at high level use. As mentioned before the percentages vary enormously between countries .

As a consequence of the complexity of Table 5 where a distinction was made between the different respondent categories it is rather difficult to get a general overview at country level. For that reason we calculated a mean problem score for each topic on the list. This was done by calculating the mean score for the respondent categories on each of the items on the problem list. If information was available from more than one teacher within a teacher categorie, first a mean score for that teacher category was calculated. All mean scores lower than .5 were recoded to 0 (no problem) and scores higher or equal to .5 were recode to 1 (a problem). Table 6 shows the significant results for schools with low (l) and high (h) level of use. The significant differences at 5\% and $10 \%$ level are indicated.

In France we find seven significant differences between the low and high level of use. There is one problem that increases at high level of use: the software is not adaptable enough. The other six problems, which are more serious at low level of use, are associated with instructional (teachers lack knowledge and insufficient expertise to help teachers) and organizational problems (no room in time table, not enough computer location space, insufficient technical assistance and insufficient training opportunities).

The differences between schools with low and high level of use in Japan are numerous. All differences show a decrease of the problems at schools with a high level of use. Interesting is that the percentage of schools in Japan with insufficient computers at low level of use is equal or higher compared to the other countries; and at high level of use the percentage of schools with insufficient computers is the lowest of the four countries. 
Table 6: Comparison on Aggregated Data for Problems Between Schools with High and Low Level of Computer Use

number of cases

Hardware

1 Insufficlent computers avallable

2 Insufficient peripherals avallable

3 Difficulty with maintenance

4 Iimitations of computers

software

5 Not enough software for instruction

6 Software too difficult

7 software not adaptable enough

8 Poor quality of manuals

9 Lack of information about software

10 Software not in instruction language

\section{Instruction}

11 Not enough supervising help

12 Integration in instruction a problem

13 Integration in curriculum a problem

14 Inappropralte for students age level

15 Teachers lack knowledge

16 Insufficient expertise to help teachers

\begin{tabular}{rr}
\multicolumn{2}{c}{ FRANCE } \\
\hline 1 & $\mathrm{~h}$ \\
114 & 116 \\
& \\
64 & 62 \\
17 & 14 \\
37 & 39 \\
41 & 40
\end{tabular}

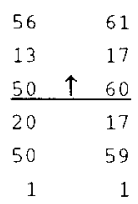

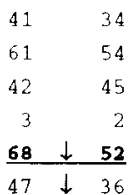

Organization

17 No room in time table

18 Not enough computer location

19 Insuff technical operating assistence

20 Computers only outside of school

21 problems scheduling enough time

22 Insuff access for teachers own use

23 Insufficient training oppertunities

24 Lack of administrative support

25 Inadequate financlal support

26 No fit in school educational policy

other

27 Not enough time to develop lessons

28 Teachers lack interest
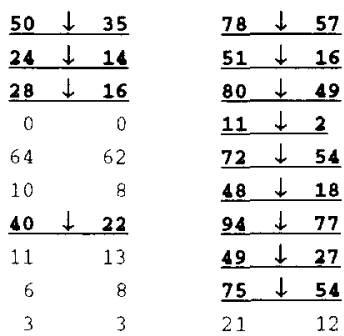

$55 \quad 58$

$34 \quad 30$

$93 \quad 92$
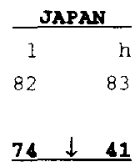

$65 \quad 57$

$40 \quad 29$

$20 \quad 28$

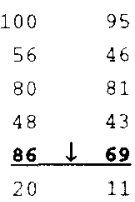

\begin{tabular}{rrr}
67 & $\downarrow$ & $\mathbf{3 7}$ \\
\hline 27 & & 28 \\
60 & & 52 \\
6 & & 6 \\
89 & & 84 \\
77 & $\downarrow$ & 64 \\
\hline
\end{tabular}

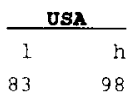

$74 \quad 58$

$53 \quad 46$

$24 \quad \downarrow \quad 13$

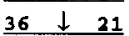

\begin{tabular}{rr}
58 & $\downarrow \mathbf{4 3}$ \\
\hline 2 & 3 \\
22 & 16 \\
12 & 10 \\
14 & 15 \\
$\mathrm{~m}$ & $\mathrm{~m}$
\end{tabular}

\begin{tabular}{|c|c|c|}
\hline 24 & 26 & 33 \\
\hline $66 \downarrow$ & 47 & 41 \\
\hline 19 & 14 & 21 \\
\hline 3 & 0 & 0 \\
\hline 63 & 55 & 64 \\
\hline 29 & 33 & 22 \\
\hline
\end{tabular}

\begin{tabular}{|c|c|c|c|c|}
\hline 42 & 39 & 35 & $\downarrow$ & 22 \\
\hline 19 & 11 & 42 & $\downarrow$ & 27 \\
\hline 25 & 20 & 24 & & 18 \\
\hline 3 & 0 & 0 & & 0 \\
\hline 25 & 32 & 36 & & 44 \\
\hline 14 & 9 & 34 & $\downarrow$ & 13 \\
\hline $14 \uparrow$ & 30 & $\underline{51}$ & $\downarrow$ & 19 \\
\hline 17 & 15 & 12 & & 5 \\
\hline & 32 & 38 & & 31 \\
\hline $10 \downarrow$ & & 0 & & 0 \\
\hline
\end{tabular}

$73 \quad 80$

$59 \quad 58$

$36 \quad \downarrow \quad 23$

$1=$ low level of computer use, $h=$ high level of computer use underlined $=$ significant $\chi^{2}$-value at ten percent level, bold and underlined $=$ significant $\chi^{2}$-value at five percent level 
The greatest difference in Japan between the high and low level of use concerns the problem: 'not enough computer location space' (18). As seen before in the context of Table 5, most of the significant differences are related to organizational aspects.

The comparison shows four (significant) differences in the Netherlands. These differences are related to limitations of computers, integration in instruction, school educational policy and training opportunities. Only the latter problem is more serious for the high level of use than for the low level.

In the USA we find eight significant differences between low and high level of use. All of them show less problems at schools with a high level of use. The differences are related to the following problem areas: availability of hardware, organizational aspects and teacher interest. The greatest difference $(32 \%)$ between the two levels has to do with the access for teachers' own use.

\section{Conclusions}

With respect to our first research question, we conclude that the most important problems of computer users are at the same time the most important reasons indicated by non-users for not using computers for instructional purposes. These problems in implementing computers in education, experienced by principals, computer coordinators and teachers, are related to what we called the conditional factors: lack of hardware, software, knowledge and time.

With respect to the second research question our conclusions are not so straightforward. Although we found great differences in the degree of computer implementation at high and low level of use within countries as well as between countries, the four most important problems are mostly the same for both levels of use.

It seems that as long as the conditional factors are not fulfilled, they have a cramping effect on the ongoing of implementing computers in education.

Besides the equality of the most important problems at both levels of use, we also found differences between the low and high level of computer use. The most important differences between schools with low and high level of use are associated with organizational aspects. Schools with high level of use have more often overcome organizational problems such as: no room in time table, not enough computer location space, insufficient technical assistance, insufficient access for teachers' own use and insufficient training opportunities.

At this moment it is not clear that, once conditional problems are solved, the integration of computers in education will proceed without major problems. From the current state of affairs we know that there is hardly any school without problems on the conditional factors. When the survey is repeated in 1992, we expect to have data from more schools which have overcome the conditional problems. It will be interesting to see whether the integration of computers in education proceeds without major problems at these schools or that a second layer of problems becomes manifest.

\section{Summary}

Although during the last decade the number of computers at secondary schools has increased considerably in many countries, only a small percentage of teachers are using computers for instructional purposes. In the COMPED study principals, computer 
coordinators and teachers were asked to indicate the obstacles which are hampering the introduction of computers in their school and classroom practice.

The results which are based on data from France, Japan, the Netherlands and USA, show that the most important problems are: lack of hardware, software, knowledge and time. These problems in implementing computers in education are at the same time the most important reasons why non-users do not use computers for instructional purposes. A comparison between the relative most intensive computer-using schools and the less intensive users shows that both groups have mostly the same problems as mentioned before. Besides, schools with a high level of computer use have more often than other schools overcome organizational problems .

\section{References}

Akker, J J H van den, Keursten, P. \& Plomp, T]. (1992). The integratıon of computer use in education International Journal of Educational Research 17, (1), 65-75

Fullan, M.G (1982). The meaning of educational change. New York Teachers College Press.

Fullan, M.G, Miles, M M. \& Anderson, S.A. (1988). Strategies for implementing microcomputers in schools The Ontario case. Toronto, Canada: Ontario Ministry of Education.

Pelgrum, W.J. \& Plomp, TJ. (1991). The use of computers in education worldwide Results from the IEA 'Computers in Education' survey in 19 educational systems. Oxford Pergamon.

\section{The Author}

ALFONS C.A. TEN BRUMMELHUIS is a researcher at the Center for Applied Research on Education at the University of Twente, Enschede, the Netherlands.

TJEERD PLOMP is Professor of Education (educational technology, curriculum technology) in the Faculty of Educational Science and Technology, University of Twente in Enschede, the Netherlands. He is chairman of IEA, the International Association for the Evaluation of Educational Achievement, and chairman of the IEA study 'Computers in Education'. 